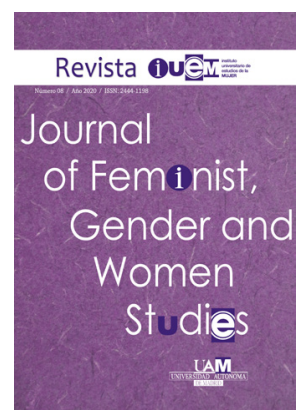

\section{Clodia Metela en el discurso "Pro Caelio" de Cicerón: un arquetipo subversivo de mujer}

\section{Clodia Metteli in "Pro Caelio" Cicero's speech: a subversive female archetype}

\author{
Blanca Berjano Rodríguez ${ }^{1, @ ~}$ \\ ${ }^{1}$ Licenciatura y Máster en Filología Clásica, Universidad Complutense de Madrid. \\ $@$ Autor/a de correspondencia: bberjano.r@gmail.com
}

\title{
Resumen
}

Este artículo estudia la representación de Clodia Metela en el discurso En Defensa de Celio de M. Tulio Cicerón. El análisis pretende extraer y describir cada uno de los elementos que componen el retrato de Clodia y que conforman un arquetipo de mujer concreto: la mulier - meretrix. Como se sabe por diversas fuentes historiográficas, Clodia Metela poseía una inmensa fortuna, por lo que meretrix no representa en este caso a una mujer que ejerce la prostitución. El orador es consciente de que tales alegaciones contra Clodia le beneficiarán en el juicio, pues el efecto censor y despectivo del término meretrix desprestigiarán la imagen de esta patricia romana y su testimonio será invalidado por los jueces y el público. Así, el orador juega con la dicotomía matrona vs. prostituta, una dualidad que se fundamenta en discursos ontológicos normativos sobre las categorías de género en la antigua Roma y que evoluciona hasta nuestros días. El personaje de Clodia también será reivindicado, en la idea de que, fueren cuales fueren sus actos reales, es descrita como una mujer que subvierte los roles de género tradicionales estipulados para una patricia romana y que se define por oposición a la matrona romana o materfamilias.

Palabras clave: Arquetipo, dicotomía materfamilias - meretrix, normatividad de género, subversión.

\begin{abstract}
This article studies the representation of Clodia Metelli in the speech In Defense of Celio by M. Tullius Cicero. The analysis of this discourse aims to extract and describe each of the elements that make up the portrait of Clodia and build a concrete female archetype: the mulier - meretrix. As it is well known from various historiographical sources, Clodia Metelli possessed an immense fortune, so in this case meretrix does not depict a woman who does sex work. Cicero is aware that such allegations against Clodia will benefit him at trial, since the censor and derogatory effect of the term meretrix will discredit the image of this Roman patrician and her testimony will be invalidated by the judges and the public. Thus, he plays with the matron vs. prostitute dichotomy, a duality that is based on normative ontological discourses on gender categories in ancient Rome (which has evolved until today). The character of Clodia will also be vindicated, in the sense that, whatever her real acts were, she is described as a woman who subverts the traditional gender roles stipulated for a Roman patrician woman and that is defined by opposition to the Roman matron or materfamilias.
\end{abstract}

Keywords: Archetype, dichotomy materfamilias - meretrix, gender normativity, subversion. 


\section{INTRODUCCIÓN}

La idea de este artículo surge con la lectura del retrato de Clodia en el discurso latino Pro Caelio, de M. Tulio Cicerón. Dicho retrato aparece constituido sobre la base de un modelo de mujer que resulta censurable y reprochable para el orador y en el contexto sociocultural al que pertenece. El objetivo ha sido combinar teorías sobre género contemporáneas con el estudio de los roles de género en la Antigüedad, siguiendo una línea de investigación interdisciplinar que surgió a partir de finales de los años setenta y que en los últimos decenios ha supuesto un avance para la comprensión y distinción de roles sociales en Grecia y Roma. Se trata, por tanto, de una combinación de estudios feministas, como los llevados a cabo por Judith Butler (1990), y de los estudios sobre género y sexualidad en Roma, siguiendo la línea de algunas investigadoras de estudios grecolatinos como Marilyn B. Skinner (1983; 2001), Suzanne Dixon (2004), Holt N. Parker (1997), Amy Richlin (1993), Sandra R. Joshel (2002), entre otras.

De acuerdo con estas líneas de investigación, Clodia puede ser estudiada como un arquetipo de género o un retrato estereotipado de mujer en los textos. La única información que se tiene acerca de ella es la que viene transmitida a través de su representación en las fuentes (principalmente, en el Pro Caelio de Cicerón), y, aunque no se sabe hasta qué punto los textos revelan el comportamiento "real" de esta patricia romana, sí demuestran que en Roma existió una mujer subversiva: una "anti-matrona" o "anti-femina". Por ello, en este artículo no se tratará de trazar la línea divisoria que existe entre el personaje creado por Cicerón y el sujeto real sino, precisamente, de deconstruir los elementos que configuran el perfil de Clodia, a fin de establecer un acercamiento al arquetipo de género metafórico que representan.

En el "marco teórico", se lleva a cabo un repaso de los aspectos sociales, culturales y políticos que condicionaban la vida de la mujer romana de clase alta, así como una indagación feminista acerca de la emancipación de la mujer al final de la República y principios del Imperio. A continuación, se estudian brevemente aquellas prácticas sexuales consideradas como ilícitas por los textos latinos y se analiza el rol atribuido a Clodia por la sociedad romana.

En el apartado de "discusión y estudio empírico" se analizan algunos fragmentos del discurso ciceroniano, abordando precisamente la distorsión de la imagen que conlleva la representación de Clodia. Se extraen los elementos discursivos que categorizan a esta mujer dentro de un arquetipo de mujer concreto y se estructuran, mediante la deconstrucción de la representación y del rol de género estipulado para una matrona romana, los elementos que configuran la categoría de la "anti-matrona" o la meretrix. Finalmente, se aborda el problema de la dicotomía antigua materfamilas vs. mulier-meretrix y se establece una analogía entre el legado clásico y la actualidad.

\section{MARCO TEÓRICO Y METODOLÓGICO}

Este apartado tiene como objetivo establecer los fundamentos teóricos que posibiliten el análisis de Clodia en el discurso Pro Caelio de Cicerón. Para ello, se sitúa en contexto sociocultural a Clodia y se circunscriben temas y conceptos generales sobre género y sexualidad en la antigua Roma, de modo que se pueda abordar el estudio del personaje ciceroniano desde una perspectiva de género.

\section{La situación de la mujer romana a finales de la República y comienzos del Imperio}

Durante los dos últimos siglos de la República (época en la que vivió Clodia) puede observarse una suerte de emancipación de la mujer romana de clase alta. ${ }^{1}$ Ello supuso un sesgo con la tradición anterior en la que su rol quedaba relegado al ámbito doméstico. ${ }^{2}$ Por un lado, las mujeres se beneficiaron de leyes que se cambiaban en provecho de los hombres y que las favorecían indirectamente, como es el caso del matrimonio sine manu: ${ }^{3}$ una mujer ganaba autonomía al haber sido casada sine manus, y al alcanzar, tras la muerte de su padre, estado sui iuris. ${ }^{4}$ Por otro lado, las campañas militares y, en concreto, la flagrante disminución de la población masculina que supuso la Segunda Guerra Púnica, facilitaron el acceso de las mujeres de clase patricia a la disposición de su patrimonio. Asimismo, se crearon nuevas leyes para que las mujeres y sus hijos pudieran heredar. ${ }^{5}$ De este modo, las mujeres ganaron autonomía administrando los bienes y haciendas. Algunas mujeres eran negotiatrices: abrían sus propios negocios y tenían a su mando a un número considerable de esclavos y libertos. El hecho de que existieran mujeres tremendamente ricas asustaba al hombre de la clase senatorial; ello se desprende de las fuentes, que abogan por el retroceso de las costumbres, la exaltación del ideal de matrona (a través de figuras como Cornelia, madre de los Gracos) ${ }^{6}$ y de la implantación de leyes retrógradas como la Lex Voconia. ${ }^{7}$

En efecto, a partir del siglo II a.n.e., el discurso de los uiri -los hombres- se enfocaba precisamente hacia la

\section{Del Castillo (1976: 243)}

2 Al contrario de lo que sucedía con la mujer griega, la mujer romana no estaba relegada al hogar, sino que participaba en banquetes, festejos y viajes junto con sus maridos.

3 En principio el matrimonio sine manu se crea para favorecer a la gens paterna. Cuando la mujer se casaba cum manu pasaba de la potestas del padre a la del marido, mientras que la casada sine manu, más frecuente a partir del siglo I a.n.e., seguía perteneciendo a la gens del padre. De este modo la mujer pasó de estar bajo el poder del marido a estar bajo una tutela, ya fuera del paterfamilias, un agnado de su padre o un tutor legal.

4 En cuyo caso se imponía la supervisión de un tutor. Un mayor grado de autonomía se alcanzaba teniendo un tutor elegido, cuya actividad se limitase a serlo a efectos legales, como fue el caso de Terencia, esposa de Cicerón (Dixon, 2004: 60).

5 En los últimos siglos de la República los pretores crearon el ius honorarium, mediante el cual se admitía la bonorum possesio a hijos e hijas emancipados de la gens paterna; en el orden sucesorio se incluyó, además de los sui y agnati, también a los cognati (incluyendo así a las mujeres).

6 Cornelia, madre de los Graco e hija de Escipión Africano, pasó a la historia como una viuda uniuira (de un solo marido) ejemplar, pues tras la muerte de su marido, rechazó un segundo matrimonio con Ptolomeo VIII. Además, ella es el ejemplo por excelencia de matrona docta. La erudición de Cornelia no contravenía ni suponía una anomalía para el statu quo; más bien al contrario, su carácter austero y el uso de sus conocimientos para la educación de sus doce hijos ayudaron a conformar el arquetipo de matrona romana ideal.

7 La Lex Voconia, promulgada en el 196 a.n.e., establecía el patrimonio máximo que una mujer podía heredar y las líneas de parentesco de las que tenía derecho a recibir herencia (Torrego, 2011: 293). 
pérdida paulatina de los valores morales romanos arcaicos. ${ }^{8}$ El relajamiento de las costumbres fue utilizado por el discurso patriarcal, especialmente cuando la mujer pudo subvertir las normas que como tal se le presumen. Téngase en cuenta que el ideal de mujer romana viene preestablecido desde la época arcaica, a través de la aemulatio de personajes como Lucrecia o Virginia, cuyos actos no solo devienen en un ideal o un exemplum, sino que además se convierten en culturalmente normativos y propios de su género. ${ }^{9}$ Así, las virtudes de las mujeres se convierten en los deberes de las mujeres. ${ }^{10} \mathrm{Tal}$ y como aparecen descritos en representaciones pictóricas, en leyendas, epitafios y monedas, dichos deberes pueden resumirse en: Pietas (la lealtad a la religión tradicional), Fides (la lealtad al marido incluso tras la muerte) y Pudicitia (pudor, recato y una conducta sexoafectiva adecuada a los parámetros normativos de la sociedad). ${ }^{11}$

Por otro lado, los autores elegíacos hablan de las doctae puellae alabando su erudición a la par que su atractivo y sus cualidades amatorias. Al igual que otras mujeres de clase alta, la docta puella había recibido una buena educación en las distintas disciplinas. Los poetas las magnifican por su conocimiento en poesía, música y danza. Este caso sí suponía una anomalía para el patriarcado romano, pues el conocimiento de las artes griegas estaba también asociado a la figura de la meretrix (la prostituta). En esta línea, mujeres como Clodia o Sempronia, procedentes de la casta noble senatorial romana, son criticadas precisamente por ser puellae doctae, y acusadas de utilizar sus conocimientos intelectuales únicamente para la seducción (Hemelrijk, 1999: 79).

Por consiguiente, las mujeres independientes o negotiatrices eran aceptadas y respetadas en la sociedad de uiri siempre que favorecieran a la economía del Estado y no contradijesen su rol degénero, esto es, que además cumplieran el papel de matrona romana. Esa autonomía económica se contrarrestaba mediante nuevas leyes o el mantenimiento de antiguas normas, como el hecho de prohibir a la mujer su participación en política o como el refuerzo y la perpetuación de un rol femenino tradicionalmente pasivo y sometido. La mujer de clase alta, cuyo ideal consistía en convertirse en una matrona de su casa, tenía más prohibiciones que libertades, pues no participaba en la creación de las leyes o las normas. ${ }^{12}$ Pese a ello, existieron mujeres que adoptaron un rol activo en sociedad, ${ }^{13}$ pero, a efectos legales, culturales y sociales

8 "We find the Catonian position set forth by Livy (...) Cato goes on to claim that Rome is suffering from avaritia and luxuria, which have entered the republic through contact with Greece and Asia" (Boyd, 1987: 191).

9 Recuérdese que el cuerpo inerme de Lucrecia sirve de excusa al padre y al marido para derrocar la tiranía del rey Tarquinio. En una interrelación que Joshel (2011: 125) califica como vampírica, los vivos -los "hombres"utilizan la muerte o el cuerpo vacío y sin vida de Lucrecia, para iniciar una lucha contra la injusticia cometida. La liberación de la tiranía y el comienzo de la vida del hombre se hace posible cuando la mujer se convierte en un objeto inerte, sin vida. Mediante el suicidio se mantiene y consolida el statu quo: una mujer deshonrada no ha de vivir sin castigo.

$10 \mathrm{El}$ término uirtus es la sustantivización de las cualidades propias y exclusivas del uir. La uirtus para los romanos es exclusiva de los hombres. Un término moral analógico para el sexo femenino sería, p.e., la pudicitia.

11 Pomeroy (1987: 208).

12 Torrego (2011: 287).

13 En los textos aparecen representaciones de mujeres que rompían el canon, como Clodia, caracterizada como Medea y Clitemnestra, figuras tenían truncada esa posibilidad emancipadora.

\section{Construcciones de lo ilícito en Roma}

Los estudios feministas y queer han creado nuevas perspectivas sobre conceptos como género, sexo y sexualidad. La "Arqueología del género", una disciplina que surge en la década de los setenta, postula que para el estudio del género en la Antigüedad se ha de contar con otras posibles construcciones de género más allá de la construcción hegemónica y binaria "hombre-mujer" (Prados Torreira, 2011: 41-42).

En El Género en Disputa (1990), Judith Butler parte de la idea de que género y sexo son categorías performativas del lenguaje y del cuerpo que se dan en un contexto sociocultural. ${ }^{14}$ La normatividad del género "exige que algunos tipos de identidades no puedan existir: aquellas en las que el género no es consecuencia del sexo y otras en las que las prácticas del deseo no son consecuencia ni del sexo ni del género." (Butler, 1990: 72). En el binarismo existente (mujer - hombre), que, según el discurso hegemónico, es a su vez la única posibilidad "natural", el género femenino queda supeditado al masculino y ello se ve corroborado por el sometimiento del sexo femenino al masculino a lo largo de la historia. Al poner en tela de juicio el carácter binario del género la autora se cuestiona, por tanto, la realidad del género. La realidad del género se entiende como algo mutable y dicha posibilidad de cambio es lo que potencia a su vez la subversión de los roles de género o el desplazamiento de los actos performativos considerados como pertenecientes a una categoría genérica.

En este artículo, estas reflexiones feministas han sido útiles para analizar el caso de Clodia, pues la normatividad de la jerarquía de género en la sociedad romana se marcaba mediante la construcción y la persistencia de arquetipos de género categóricos cuyas prácticas sexoafectivas eran consideradas bien como lícitas (unión del uir - hombre y la femina - mujer), bien como ilícitas: cinaedus, pathicus, mulier, uirago, tribas, moecha. Según esta jerarquía binaria de los roles de género y sexuales, el uir debía adoptar un rol activo y la femina, un rol pasivo (Parker, 1997: 55). La construcción de lo ilícito o de lo subversivo consiste en la estructuración de categorías sexuales que los textos transmiten como comportamientos perversos. El cinaedus, pathicus, impudicus o diatithemenos conforma la categoría de sujetos detractores del género masculino que adoptan un rol sexual pasivo, preferiblemente con uiri. ${ }^{15} \mathrm{El}$ cunnilinctor procura placer de forma pasiva a una mujer que suele ser descrita también como perversa. La tribas o las tribades entran dentro de la categoría de mujeres que adoptan un rol activo con otras mujeres (Hallet, 1997: 255). La moecha -literalmente "adúltera" - o la uirago - "que actúa como un

femeninas icono de lo transgresor y del desastre familiar. Cf. Cicerón, Pro Caelio, 18, y Quintiliano, Institutio Oratoria, VIII, 6, 53, respectivamente.

14 "Como consecuencia, el género no es a la cultura lo que el sexo es a la naturaleza; el género también es el medio discursivo/cultural a través del cual la 'naturaleza sexuada' o un 'sexo natural' se forma y establece como prediscursivo, anterior a la cultura, una superficie políticamente neutral sobre la cual actúa la cultura" (Butler, 1990: 55,56).

15 Parker (1997: 58). 
hombre", adoptan un rol sexual activo (Parker, 1997: 48). ${ }^{16}$

Como se demostrará en el análisis de la representación de Clodia, a estas diversas categorías se podría añadir la de la mulier-meretrix. El término, en el caso de Clodia, no se refiere a la mujer que ejerce la prostitución como tal, sino a alguien cuyo comportamiento sexoafectivo no se aviene a las prácticas normativas estipuladas para una matrona romana. La mulier-meretrix es descrita como una mujer que adopta un rol sexual activo y, por ende, no es tratada como una femina, ni mucho menos como materfamilias.

Si se tiene en consideración la existencia de personas, como el cinaedus o las tribades, que según los textos subvertían los actos sexuales normativos, surge la cuestión de si se podría entonces hablar de una subversión del género en la antigua Roma, tal y como la entendemos hoy en día. Como apunta Parker a partir del ejemplo de Mamerco Escauro en el texto de Séneca, ${ }^{17}$ no se tiene constancia histórica de la existencia de colectivos que en aquel entonces defendieran su identidad de género con un objetivo político y reivindicativo. Sin embargo, lo que sí queda claro es que el discurso normativo en torno a los roles de género y los roles sexuales en la antigua Roma no era una premisa bajo la cual se regían todos los sujetos, puesto que los textos, si bien con intención paródica o de censura, nos transmiten la existencia de otras identidades que rompían con el canon normativo de la época.

\section{DISCUSIÓN Y ESTUDIO EMPÍRICO}

El primer apartado de este capítulo ofrece una serie de datos biográficos sobre Clodia Metela, de modo que se facilita la comprensión de los fragmentos del discurso de Pro Caelio. En los capítulos siguientes, el propósito será analizar la manera como está retratado el personaje de Clodia. La deconstrucción de dicho retrato trata de evidenciar la oposición materfamilias-mulier / meretrix que preside la totalidad del discurso. Así, se exponen aquellos aspectos del personaje de Clodia que difieren de la normatividad del rol estipulado para una mujer de clase alta, una materfamilias.

\section{¿Quién era Clodia Metela?}

Clodia pertenecía a la gens Claudia, una de las familias patricias más influyentes de Roma. Durante la República, los Claudii ocuparon una total de veintiocho consulados y cinco dictaduras (Skinner, 2011: 23). El padre de Clodia fue Apio Claudio Pulcro (cónsul en el año 79) y se desconoce quién fue su madre. Ambos murieron prematuramente (Skinner, 2011:

16 Sin embargo, las alusiones en la literatura a una uirago suelen dirigirse a mujeres cuyas hazañas requieren la valentía de un hombre o que tienen la "dureza" de un hombre, como Casandra en la tragedia Agamenón de Séneca.

17 "Scaurus, in response to something Pollio had said, offhandedly remarked, "fuck you". He then changed it around by adding, "But I'd prefer you to fuck me". Here we have a picture of a man (...) who presents himself as a cinaedus, who makes a joke of one of the worst Roman insults. (...) Does this mean, however, that the constant depiction of cinaedi points to men who constantly depicted themselves as cinaedi? Does this qualify as a sub- or counterculture? I do not believe the evidence is sufficient to say, though the example of Scaurus points to a way in which the cultural type of the cinaedus might have been deployed for individual self-fashioning" (Parker, 1997: 62).
52). Probablemente Clodia fue la primera de sus hermanos y hermanas, todos nacidos en la década del 90 a.n.e. ${ }^{18}$

Los Claudii Pulcrii y los Metelli tenían lazos familiares. A la edad de trece o quince años, según la costumbre romana de casamiento para las jóvenes patricias, fue casada con su primo Quinto Metelo Céler. ${ }^{19}$ Metelo era partidario de los optimates, partido conservador, fue cónsul en el 60 y falleció en el 59. No se tiene constancia de que Clodia volviera a contraer matrimonio después de la muerte de su marido, pero Clodia y Metelo estuvieron casados al menos durante veinte años. Gracias al testimonio de Cicerón, se sabe que vivieron en una casa en el Palatino y que Clodia tenía, además, una villa con jardines junto al Tíber. Asimismo, se conjetura que quizás tuviera otra propiedad en Bayas. De ello se deduce que Clodia amasó una inmensa fortuna, una vez fallecido Metelo, y que tuvo a su disposición dicho patrimonio, aunque probablemente estuviera bajo la tutela de su hermano Clodio.

Por las cartas que Cicerón escribe a Ático, se sabe que el marido de Clodia tenía desavenencias con su cuñado, Clodio Pulcro. Al parecer, Clodia apoyaba más la causa política del hermano que la de Metelo. Sin embargo, Clodia también le pasaba información a Ático, amigo de Cicerón y enemigo acérrimo de Clodio, lo cual resulta paradójico. Sea como fuere, Clodia no actuaba conforme al rol estipulado de esposa y hermana, pues probablemente tuviera sus propios intereses políticos. ${ }^{20}$

Por último, Clodia también ha pasado a la historia por haber mantenido numerosas relaciones amorosas; ${ }^{21}$ uno de los vínculos más famosos es el que mantuvo con Marco Celio Rufo y que transmitió Cicerón en el discurso que aquí se estudia.

\section{El día del juicio contra Celio Rufo}

El discurso de Cicerón Pro Caelio fue pronunciado el día 4 de abril el año 56 a.n.e. El acusador principal de la querella fue Lucio Sempronio Atratino, y los acusadores secundarios (subcriptores) fueron Lucio Herenio Balbo y Publio Clodio Pulcro, hermano de Clodia Metela.

A Celio se le acusaba de violencia criminal contra el

18 Clodia pudo haber nacido de una unión anterior de Apio Claudio con otra mujer, en cuyo caso sería hermanastra del resto de hijos e hijas de Apio Claudio.

19 Nótese el uso en castellano de la voz pasiva, pues para formalizar el matrimonio en la antigua Roma el consentimiento de los padres era indispensable: "En efecto, el primer paso que hay que dar para entender el funcionamiento del matrimonio romano es la consideración de la figura paterna de ambos cónyuges como desencadenante real del acto matrimonial” (López Gregoris,, 1998: 96). Por otro lado, el léxico empleado para contraer matrimonio en latín revela una realidad sociocultural en la que la mujer era sujeto pasivo, dado que la expresión de matrimonio por parte de la mujer siempre se da con verbos intransitivos, mientras que la de por parte del padre o el marido se da con verbos transitivos (López Gregoris 1998: 101).

20 Skinner (1983: 281).

21 Ha pasado a la historia como la Lesbia del poeta Valerio Catulo. Apuleyo en Apología $(10,5)$ la identifica con Clodia Metela. Algunos investigadores aceptan la identificación de Lesbia con Clodia como cierta (López Fonseca, 2004: 144 y Cantarella, 1996: 163); otros mantienen cierto escepticismo (Skinner, 2011: 132 - 136). Catulo la denomina Lesbia en honor de la poeta griega Safo de Mitilene. El poeta, entre otras caracterizaciones, describe a Lesbia como a una puella docta, una mujer versada en las artes y la literatura. 
estado (vis contra rem publicam) por su involucramiento en una sublevación contra el Estado en Nápoles y por su supuesta colaboración en la conjuración de Catilina. Se le acusaba también de haber atacado a una delegación de embajadores alejandrinos y haber asesinado a Dión, responsable de aquella embajada. Según la historia que transmite el discurso ciceroniano, la acusación estipulaba que Clodia habría prestado un oro a Celio con el que supuestamente pagó a los sicarios que acabaron con la vida de Dión, y que jamás devolvió a su dueña. Después, Celio habría intentado envenenar a Clodia, para que esta no pudiera testificar contra él.

La defensa fue asumida por el propio Celio, por Marco Licinio Craso y Marco Tulio Cicerón. Los dos primeros defendieron la primera parte de la acusación, con lo que a Cicerón le quedaba responder a la parte de la imputación testificada supuestamente por Clodia, i.e. el préstamo del oro no devuelto y el intento de envenenamiento.

La etapa en la que se desarrolla el juicio es una época de convulsión política, de luchas entre clases y de rivalidades entre las dos facciones de poder de aquel entonces: los optimates y populares. Cicerón es consciente del deterioro de las instituciones y de la alteración del orden político; es por ello que apela en el discurso a la concordia ordinum (la unión de los órdenes ecuestre y senatorial), a la defensa de las instituciones y a la restauración de las antiguas normas morales (McCoy, 2006: 177).

\section{El retrato de Clodia Metela en el Pro Caelio de Cicerón}

Siguiendo las líneas recientes en investigación de la mujer romana (Marilyn B. Skinner: 1983, 2011; Suzanne Dixon: 2004; Amy Richlin: 1993), Clodia puede estudiarse como un arquetipo mitificado y simbólico de mujer. ${ }^{22}$ Aparte de la probada historicidad de Clodia, el vacío que existe entre la representación y el personaje real es evidente y en gran medida inescrutable, como una suerte de agujero negro. Con el fin de reinterpretar el arquetipo despectivo que representa Clodia en el texto de Cicerón, se analizarán a continuación algunos fragmentos del discurso ciceroniano.

A lo largo del discurso, Cicerón incide reiteradas veces en que es Clodia la causante de todos los males de Celio: "En efecto así, jueces, descubriréis lo que, cuando llegue a ese momento, os mostraré: que esta Medea Palatina y el traslado de domicilio fueron para el joven la causa de todos sus males..." (§18). ${ }^{23}$ Medea Palatina, el epíteto con el que Cicerón denomina a Clodia, tiene la función retórica, como indica M. Skinner, de desacreditar la imagen de esta mujer en pro de victimizar a Celio (Skinner, 1983: 275). La utilización de

\footnotetext{
22 “These women are symbols, not 'real women' (...) Women's portraits in the Roman tradition are often quite realistic, but they, too, fall into certain patterns, and sometimes individual heads seem to have been imposed on standard bodies" (Dixon, 2004: 56). "Fortunately for Clodia, however, none of the evidence cited above should be taken at face value. Catullus' erotic poems cannot possibly be treated as historical documents (...) We must harbor similar misgivings about the damaging charges contained in the Pro Caelio. As several recent studies have shown, much of the persuasive effect of this speech arises from Cicero's clever manipulation of female stereotypes present in the minds of the jurors" (Skinner, 1983: 274).
}

23 Traducción propia de los fragmentos del discurso Pro Caelio, ed. Austin (1960). la figura mitológica, con una fuerte carga dramática e irónica, establece un paralelismo entre Medea, que lleva su hogar a la ruina con su acto de venganza contra Jasón, y entre esta patricia romana. La idea de Clodia como una mujer que ha invertido los valores morales de una familia, se repite en el $\S 34$, párrafo en el que Cicerón, en una idolopeya de Apio Claudio, reprueba la actitud de esta, señalando que una mujer respetable debe tener relación únicamente con sus familiares, o en todo caso con los amici del marido. ${ }^{24}$ También le reprocha a Clodia su excesiva familiaridad con Celio, un hombre extraño a la familia y, para colmo, más joven que ella.

La imagen de Clodia se contrapone a aquella que se ofrece de Celio, un joven inocente y corrompido por esta dama de la nobilitas: "Echaste el ojo a un joven vecino, su candor y su semblante, su rostro y ojos te impresionaron; quisiste verlo cada vez más..." (§36). La imagen de Celio como un adulescentulus refuerza la idea de que este ha sido una víctima de la terrible Medea Palatina. De hecho, en Pro Caelio, Celio es presentado como un juguete sexual de Clodia. ${ }^{25}$ No se sabe con exactitud la fecha de nacimiento de Celio, como tampoco la de Clodia, pero se piensa que este pudo haber sido en torno al año 80 a.n.e., por lo que en la fecha del juicio tendría unos treinta años (Clodia tendría como mucho diez años más que él). Sin embargo, la imagen que se dibuja de Clodia es la de una dama entrada en edad que utiliza a jovencitos para su propio deleite personal. ${ }^{26}$

El abandono de Celio es lo que, según Cicerón, causó en Clodia un sentimiento de despecho e ira que la llevó a montar todo el espectáculo del juicio basándose en conjeturas indemostrables. En el $\S 36$ Cicerón pronuncia otro soliloquio en el que interpreta a Clodio con un discurso en el que este le reprocha a su hermana el comportarse como una histérica y el estar molesta ante el rechazo de Celio, cuando en su casa junto al Tíber tiene la facilidad de encontrar a todos los jóvenes que ella quiera: “¿Por qué causas este alboroto, hermana? ¿Por qué haces locuras? ¿Por qué comenzando a gritar haces de una cosa pequeña una grande?"

La última frase de $\S 31$ cierra con una máxima: Res est omnis in hac causa nobis, iudices, cum Clodia ("Para nosotros, jueces, toda esta causa se relaciona con Clodia"). De nuevo el orador insiste en que la acusación de Celio de vis contra rem publicam no tiene lugar en el juicio, pues se pretende la entrega del joven simplemente para satisfacer el deseo y el capricho de Clodia: “...una ley que, ${ }^{27}$ después de apagar aquel famoso fuego de mi consulado, sirvió para extinguir los restos humeantes de la conjuración; y ahora, al amparo de esta ley, se exige que se condene al joven Celio, no para castigar delitos contra el Estado, sino para satisfacer

\section{Geffcken (1995: 34)}

25 It is noteworthy that in his impersonation of Clodia's brother, the orator made "Publius" dismiss her new acquaintance quite offhandedly as an adulescentulus - literally, "an insignificant youth", a term that here carries much the same implications as "toy-boy" (Skinner, 2011: 106).

26 Las relaciones amorosas entre mujeres y hombres en Roma seguían la pauta normativa, mediante la cual la mujer no debía tener más edad que el hombre en una relación que acatara las normas del pudor. Por el contrario, la mujer romana era casada llegada su pubertad, y en algunos casos con hombres hasta veinte años mayores que ellas.

27 Se refiere a la Lex Lutatia de vi, por la cual se procede a la acusación de Celio de vis contra rem publicam y que era aplicada especialmente en casos de sedición o conjura (fue la misma que se usó para juzgar la Conjuración de Catilina). 
los placeres y los caprichos de una mujer" (García González, 2009: 125).

Clodia como motor y fuente de la acusación contra Celio desvela un papel activo de la mujer en el caso. La exageración ciceroniana la implica dentro de unas caracterizaciones impropias para una matrona romana. El poder del personaje de Clodia es precisamente el hecho de ser instigadora de toda la causa contra Celio, de ser la acusadora y la fuerza promotora de aquel juicio. Sin embargo, en la realidad, la mujer romana no tenía autoridad legal alguna; su propia acusación y defensa le venían negadas por el hecho de ser mujer. La acusación fue defendida por los subcriptores, quienes habrían utilizado a Clodia como testigo de los hechos.

En un juicio como este, en el que se imputa a Clodia la responsabilidad de toda la acusación, aludiendo a un despecho amoroso, exaltando su carácter histérico y criticando su palabra o su testimonio (cuando no ha podido interceder por sí misma), la causa, en principio contra Celio, se vuelca totalmente contra ella. Cicerón utiliza, por tanto, la única presa fácil de aquella situación: la mujer a la que la palabra le ha sido negada por las leyes. Con todo, la decisión de prestar su testimonio a los acusadores de Celio, en cualquier caso, demuestra un papel relativamente activo de Clodia en el juicio.

Otro de los recursos discursivos que utiliza Cicerón en defensa de Celio y que sin duda consigue inclinar la balanza en contra de Clodia es su caracterización como una mulier y una meretrix. El término categórico mulier, utilizado en numerosos episodios en el discurso, se contraponen al concepto de femina. ${ }^{28}$ Clodia será definida a lo largo del discurso como mulier, no femina, domina, ni materfamilias, salvo para usos sarcásticos como en el §57: "En una casa como esa, en la que la madre de familia vive como una prostituta..." En la retórica ciceroniana $-\mathrm{y}$ en la narrativa historiográfica en general-, el término femina va usualmente en correlación con el estatus social, pero también con la intención de respetabilidad que el autor quiere conceder a la mujer de la que habla. Femina denota, por tanto, aristocracia, respetabilidad y comportamiento virtuoso, acorde con el ideal romano (Santoro L'Hoil: 40). El uso del término mulier, en principio usado para designar a las mujeres de las clases sociales inferiores (como esclavas y libertas), sirvió también para definir a aquellas mujeres que se alejaban del canon ideal de la nobilitas. ${ }^{29}$ Cicerón claramente juega con la dicotomía femina-mulier con la finalidad persuasiva de presentarla como el personaje antagónico de la femina o materfamilias.

En el $§ 1$ se establece ya el primer paralelismo entre

28 El término femina es usado dos veces en todo el discurso; la primera en el soliloquio de Apio Claudio el Ciego §34, para hacer referencia a las mujeres de la familia Claudia. La segunda en el $\$ 63$ talis feminae familiaris..., para resaltar de forma irónica cómo Clodia, una "fémina", tiene demasiada familiaridad con el responsable de los baños (Santoro L'Hoir, 1992: 64). Femina es utilizado por consiguiente con motivación sarcástica.

29 "The nouns vir and femina came to signify the upper classes, while homo and mulier applied to everyone else. (...) Conversely, homo and mulier, because of their use to indicate members of the lower orders, including slaves and freedmen, many of whom were foreigners, came to connote foreign vices, avariciousness, luxury, association with the mob, conspiracy, or participation in an innovative peregrine cult. Consequently, homo and mulier can represent the antithesis to the oligarchic ideal. Used as terms of abuse, they figure prominently in invective against members of the aristocracy" (Santoro L'Hoir 1992: 1-2).
Clodia y la imagen de la meretrix. El uso del sustantivo meretrix es un topos discursivo que tiene la función evidente de convencer al jurado de que Clodia no se comporta como una matrona respetable. En numerosos apartados del discurso (Cf. §37; §38; §48; §49; §50; §57), y particularmente en el §49, se crea la imagen pictórica de la prostituta "desvergonzada y atrevida" (proterva, procax), con una forma concreta de moverse, de abrazar, de besar, de mirar, de hablar, etc.:

Si una mujer no casada hubiera abierto su casa a la pasión de todos y se hubiera instalado abiertamente en la vida de la prostitución, hubiera decidido servirse de los banquetes de hombres totalmente desconocidos, si esto lo hiciera en la ciudad, si en los jardines, si en la animación de Bayas, si finalmente de tal modo se comportara no solo en su andar, sino en su tocado y su séquito, no solo en el ardor de su mirada, en la libertad de sus palabras, sino también en el abrazo, el beso, en los actos, en el paseo por mar, en los banquetes, que pareciera no solo una prostituta, sino incluso una prostituta desvergonzada y atrevida $(. . .)^{30}$

La desvergüenza de Clodia aparece también en el §35: "De cierto los acusadores se jactan en palabras como "pasiones», "amores», "adulterios», "baños en Bayas», «playas», «banquetes», «juergas», «canciones», "conciertos», "paseos en barco» y esto mismo dan a entender que nada dicen sin tu consentimiento." En este párrafo Cicerón hace alusión a claros ejemplos de "excesos y lujuria", y la frase nihil se te invita dicere ${ }^{31}$ demuestra inexorablemente la indiferencia de Clodia con respecto a sus propios actos. Es posible plantear la posibilidad de que Clodia hubiera permitido a los subcriptores de la causa la utilización de algunos detalles de su vida privada para poder probar su vínculo con Celio, lo cual reflejaría la imagen de una mujer a la que, efectivamente, no le preocupaba excesivamente que su forma de vivir saliera a la luz.

Es interesante, por otra parte, observar detalladamente cuáles son los atributos que configuran la imagen de la mulier-meretrix en el discurso de Pro Caelio:

- Clodia abre las puertas de su casa a la pasión de todos y es demasiado conocida por todos (non solum nobili, sed etiam nota §31). En el §32 "amiga de todos antes que enemiga de alguno" el orador juega con la connotación sexual del término "amiga" en latín. ${ }^{32}$ Además, presentando a Clodia en esta dicotomía (amica - inimica) se refuerza la idea que aparece repetidamente a lo largo de todo el Pro Caelio: Clodia es amiga de todos, i.e. es una meretrix, pero enemiga de la persona a la que acusa: Celio. Para más inri, la casa de Clodia no es el hogar de una materfamilias; reina el caos, los esclavos han invertido su rol de sirvientes, pues conviven con la domina, y los hombres entran y salen a su antojo (\$57). La imagen de la domus de Clodia es claramente paródica y refleja la escena de un lupanar, en la que hay hombres que entran y salen con frecuencia.

- Asiste a banquetes de hombres desconocidos. Por norma general, la matrona romana podía ir a banquetes, pero

30 Traducción propia de Cic. Cael. 49. ed. Austin (1960).

31 Cic. Cael. 49. ed. Austin (1960).

32 "Amicus is properly translated...as male friend (...) Amica, the feminine form of this noun, is best translated not simply as female friend, but as girlfriend" (Hejduk, 2008: 14). 
siempre acompañada de su marido o de su tutor legal. Cicerón, dotando de un falso misterio al asunto, da a entender que una mujer que va a banquetes de "hombres desconocidos" va buscando algo: ¿Quiénes son esos hombres desconocidos y qué quiere de ellos? ¿Sexo por dinero? Respuesta poco probable, pues Clodia tenía, como ha probado M. Skinner, cuantiosas propiedades y bienes, lo que también era sabido por Cicerón y el jurado (Skinner, 1983: 273). Entonces, quizás buscara clientelismo político, un amicus o varios a quienes hacer préstamos ${ }^{33}$; o bien, aceptando la teoría de que Clodia tenía diversos amantes, quizás se encontraba con estos en las fiestas. Pueden ser ciertas varias de estas suposiciones o ninguna.

- Busca clientes paseándose por la ciudad, los jardines y en Bayas, así como en los paseos por mar y banquetes.

- Una determinada forma de andar: Clodia camina como una meretrix. Esta apreciación de Cicerón desvela la propia concepción del orador acerca de cómo debía o no caminar una matrona romana.

- Una forma de vestir: Las fuentes transmiten que existían dos tipos de vestimenta diferenciados para las matronas y las prostitutas; las primeras llevaban la stola y las segundas, la toga muliebris; una matrona no debía llevar la vestimenta togada si no quería ser confundida con una prostituta. Las fuentes ejemplifican y expresan lo que una matrona romana debe y no debe llevar y cómo su vestimenta refleja o no su pudicitia. La castidad y el pudor en la forma de vestir residían en que la mujer no se dejara ver (así lo estipula Séneca, Controversiae 2.7.3.). ${ }^{34}$ Con todo, la desviación en la norma de la vestimenta existía, p. e. la seda de Cos, famosa por su transparencia, fue utilizada tanto por mujeres ricas como por prostitutas, por lo que en ocasiones compartían modas y formas de vestir (Olson, 2006).

- Una compañía de gente concreta: A lo largo del discurso, se relaciona a Clodia con su hermano Clodio, enemigo acérrimo del orador. Cicerón se había visto forzado al exilio en el año 58, cuando Clodio, como tribuno de la plebe, presentó un proyecto de ley para condenar al destierro a aquellos magistrados que habían dado muerte a otros ciudadanos sin juicio previo (como era el caso de Cicerón tras la detención de los participantes en la conjura de Catilina). Por ello, Cicerón no duda en desacreditar también a Clodio, insinuando una relación de incesto entre los dos hermanos (Cf. §32; §36). ${ }^{35}$ Esta alusión ha de entenderse como un leitmotiv con una enorme repercusión en la imagen pública de Clodio y Clodia, que condicionaría la decisión final del jurado. Además, la representación de Clodia a lo largo de todo el discurso como prostituta allanaba el terreno para esta nueva caracterización de su personaje; su impudicia era tal que cualquier transgresión de las normas socioculturales

33 Algunas patricias hacían préstamos a un amicus, como el de Caerellia a Cicerón (Dixon, 2004: 64).

34 "Ideal clothing is stressed precisely because the social and vestimentary definitions of women in Roman antiquity were not as sharply delineated as the exemplar demanded" (Olson, 2006: 201).

35 Clodia y Clodio son representados como individuos que no se rigen por las normas morales más básicas y primitivas de su sociedad. El incesto contradice las reglas y ritos conformados en la sociedad desde tiempos primitivos y desfavorece el buen funcionamiento ya no solo de una familia o gens, sino del Estado mismo. El incesto entre hermanos era un tabú en Roma, los escritos etnológicos de Plutarco o Varrón así lo expresan (Moreau, 1978: 41). podía atribuirse a su nombre. Por otro lado, Clodio ya había sido anteriormente acusado de incesto con otra de sus hermanas, de manera que la utilización de un viejo rumor no debía causar la impresión de inventio en los participantes del juicio. ${ }^{36}$ Cicerón utiliza el tabú del incesto con fines retóricos, desacreditando así la cooperación que existía entre ambos hermanos y sumando a la imagen de Clodia otro aspecto más de su perversión. ${ }^{37}$

- Una mirada ardiente: La flagrantia oculorum de Clodia aparece también en las cartas que Cicerón escribe a Ático (Att. 2.12.2; 2.22.5), donde la apoda Boẃrıs, "ojos de buey", epíteto homérico de Hera, haciendo alusión a sus grandes ojos negros y estableciendo a su vez una analogía con la diosa. ${ }^{38}$ No deja de ser ambiguo y paradójico que el orador describa con tal epíteto los ojos de Clodia, al tiempo que la critica por el ardor de su mirada. Sin embargo, hay que tener en cuenta que una forma de mirar provocadora y seductora era incompatible con el deber de pudor y recato estipulado para una matrona romana.

- Libertad en sus palabras: Dentro de los deberes de las mujeres, (pietas, fides, pudicitia), el silencio se consideraba una virtud femenina. Para Cicerón, Clodia transgrede el deber del silencio y del pudor.

- Forma de abrazar y forma de besar: La pudicitia para la mujer se manifestaba a través de la pasividad y el recato. Los autores describen de forma peyorativa a las mujeres que actúan como "hombres" y cuyos actos subvierten su rol de género contrariando el statu quo. Estas no se categorizan como feminae, toman un rol sexual activo y, por ende, sus actos son criticables. ${ }^{39}$

Algunos investigadores asemejan el personaje creado por Cicerón al arquetipo femenino del fatale monstrum. ${ }^{40}$ Quizás haya influido para esta calificación los párrafos 59-60 del Pro Caelio: “¿Se atreverá semejante mujer, salida de esta casa, a hablar de la velocidad del veneno?" (...) ¿No sentirá horror de lo que cuentan aquellos muros de lo que sucedió

36 En la actualidad, la relación incestuosa entre ambos se considera un rumor extendido. Como señala Skinner (2011: 63), el tema del incesto empezó, a partir de la primera acusación, a formar parte de un rumor generalizado en torno a la familia de los Claudii, con Clodio a la cabeza como imagen de lo perverso e impúdico.

37 "Ciceros Attacke auf die Geschwiater hat schliesslich Erfolg: Caelius wird freigesprochen, Clodia als unglaubwürdig dargestellt und der politische Feind Clodius über die Diffamierung der Schwester diskreditiert (...) Die Invektiven Ciceros hatten eine gesellchaflich hervorgehobene Position Clodia unmöglich gemacht, so dass die enge öffentliche Kooperation zwischen den Geschwistern ein Ende fand" (Harders, 2005: 74).

38 Skinner (2011: 66).

39 "The active woman, the virago, tribas, or moecha, will invert the values of the femina (...) It is clear, then, that any woman who enjoys sex is abnormal and masculine. The sexually active woman is the prostitute or the adulteress, who inverts the values of the society (...) The anomalous woman, the woman active in any sense, is attacked as sexually active and hence monstrous -Sempronia, Fulvia, Lesbia, Messalina-" (Parker, 1997: 58-59).

40 "En este mundo no se clasifican las diversas conductas por el sexo, el amor a las mujeres o a los muchachos, sino por la actividad o la pasividad: ser activo es ser un macho, sea cual fuere el sexo del compañero pasivo. En tomar placer virilmente o en darlo servilmente está la clave. La mujer es pasiva por definición, salvo que sea un monstruo y, en este asunto, no tiene voz" (Veyne, 2010: 154). También: "The pictures of Sallust's Sempronia, or Cicero's Clodia or Sassia, or Catullus' Lesbia (...) Such a woman is a monster who violates boundaries" (Parker, 1997: 58). También Boyd utiliza el término fatale monstrum como la imagen de la perversión del orden natural (Boyd, 1987: 200). 
aquella funesta y dolorosa noche?" Estas líneas del discurso pueden entenderse como una alusión al asesinato de Metelo por parte de Clodia. ${ }^{41}$ De este modo, Clodia se convierte ya no solo en una prostituta, sino en una prostituta asesina de su propio marido que comete incesto con su hermano (o hermanastro) Clodio. Según M. Skinner (1983), la acusación del envenenamiento está al mismo nivel que la de la prostitución o el incesto, esto es, son invenciones retóricas utilizadas para revertir la acusación y volcarla contra Clodia, culpabilizándola y representándola como a una mujer que subvierte los roles tradicionales de las matronas y que, por tanto, es peligrosa para el buen funcionamiento del Estado romano.

\section{La mulier-meretrix: un arquetipo diacrónico de mujer}

Sin duda hay algo más que una alusión a la prostitución detrás del término meretrix en Pro Caelio. El uso de este epíteto despectivo, como ya se ha indicado anteriormente, forma parte de la inventiva retórica del orador; ciertamente tanto Cicerón como el jurado tienen en sus mentes la imagen y el retrato de esa supuesta prostituta. En el discurso hay una utilización transversal de lo erótico-ilícito-prohibido, aunque todo el párrafo gire en torno a una narrativa de lo coercitivo, reprochable o censurable para una matrona romana. En efecto, se resaltan las aptitudes amatorias y la belleza natural de Clodia, al tiempo que esta es objeto de censura. La censura desvela a una mujer con un rol social, político y sexual activo: era una meretrix, porque se atrevía a adoptar roles tradicionalmente masculinos, lo que implica iniciativa y libertad en sus actos.

Paradójicamente, la existencia de un arquetipo de mujer que subvierte los roles de género a su vez sustenta el propio sistema que lo prohíbe, puesto que funciona por oposición al canon. Así, el sistema de oposición dicotómica, matrona ideal vs. mulier-meretrix, o Lucrecia vs. Clodia (ambos ejemplos hiperbólicos) sostiene y perpetúa el statu quo. Esta dualidad es diacrónica, pues viaja en el tiempo y llega hasta nuestros días, adquiriendo otros nombres, adaptándose a otros contextos, pero siempre reflejando una única posibilidad dual para la mujer. Tal y como explica Virginie Despentes:

"La dicotomía madre-puta está dibujada artificialmente sobre el cuerpo de las mujeres... Esta separación no procede de un proceso natural, sino de una voluntad política. Se condena a las mujeres a estar escindidas en dos opciones incompatibles." (2007: 69).

El arquetipo de la meretrix es censurado precisamente por el hecho de no atenerse al comportamiento normativo de una patricia romana. Por ello, resulta interesante reivindicar el personaje de Clodia, recordando las palabras de Cicerón: nihil se te invita dicere (§49). La mulier-meretrix romana representa a la mujer subversiva y peligrosa para el statu quo. Clodia no se atiene a un canon, no representa un solo papel de todos los que existían para la materfamilias, desfavoreciendo así la perpetuación de las instituciones familiares y estatales. Por tanto, el arquetipo de Clodia

41 Según el discurso de Cicerón, Clodia podría ser la asesina de Metelo, que falleció de forma repentina bajo circunstancias sospechosas. También Quintiliano en Instituciones Oratorias (8. 6.53) expone que Celio llamó a Clodia "Quadrantaria Clytemnestra". desvela no solo lo que se considera como ilícito en la Roma del siglo I a.n.e, sino también el miedo a que los topos que configuran las prácticas y realidades prohibidas existan y se manifiesten en la cultura realmente. El efecto censor refleja el miedo a ese "tipo de mujer" con poder de hacer sollicitare (tambalear) el vasto núcleo moral que regía las vidas de las poblaciones bajo el gobierno romano.

\section{CONCLUSIONES}

En este artículo se ha realizado un estudio de la representación de Clodia Metela en fragmentos escogidos del discurso ciceroniano, Pro Caelio. Se parte de la premisa de que el discurso no puede considerarse en su totalidad como un documento histórico para conocer aspectos biográficos de la vida de esta patricia romana. En investigaciones contemporáneas sobre la figura de Clodia se llega a una misma conclusión: ella no es todo lo que nos cuentan los autores. Por esta razón, en este trabajo no se ha realizado un estudio prosopográfico de Clodia, sino más bien se han analizado cada uno de los elementos que definen su personalidad en el Pro Caelio y que constituyen la categoría genérica de la mulier-meretrix en la antigua Roma.

La metodología que se ha seguido es el análisis de la serie de elementos comunes, topos y leitmotivs que constituyen la construcción de un arquetipo de mujer en el texto de Cicerón. Clodia, pese a que pertenecía a la nobilitas romana, es descrita como una mulier, nombre genérico que denota un estrato social inferior por oposición a femina. Partiendo de las reflexiones de Judith Butler sobre el género (1990), se ha indagado en la connotación del término mulier asociado a la imagen de la meretrix, y se han analizado los actos performativos asociados a la figura de la muliermeretrix por oposición a los de la materfamilias. La crítica al arquetipo se da mediante la exposición de actos asociados a los roles tradicionalmente masculinos: por un lado, Clodia participa activamente en política, pues va a juicio contra Celio, por otro, adquiere un rol sexual activo (aunque no sabemos con certeza de qué modo ni con quién). Por esta razón, se concluye que la mujer que es descrita con un rol activo en sociedad es calificada, según los intereses del vir, como mulier-meretrix.

Este modelo de mujer constituye un exemplum de lo subversivo a la vez que perpetúa las caracterizaciones de lo censurable y reprochable para la mujer romana. Esta censura de la "anti-femina" o la "anti-matrona" se da como consecuencia de la ansiedad que provoca la propia transgresión, desviación o subversión de los roles de género en la antigua Roma. Por ello, aunque no se sepa con certeza cómo era Clodia, debajo de la imagen ciceroniana podría subyacer una mujer cuyos actos -sean cuales fueren- no se adecuaban a la normatividad del rol de género femenino y trastocaban de algún modo el firme patriarcado romano. Por esta razón y porque presenta ciertos paralelismos con la actualidad, el arquetipo de la meretrix ha sido reivindicado en tanto que subversivo. Ello corrobora, además, que la normatividad de género se construye sobre la base de un núcleo epistemológico y moralizante que integra la sexualidad y el deseo, y que se transmite a lo largo de la historia. 


\section{REFERENCIAS}

Austin, Gregory R. 1960. M. Tulli Ciceronis: Pro Caelio Oratio, Oxford, Clarendon Press.

Beauvoir, Simone. 1949. Le Deuxième Sexe I. Les faits et les mythes, Paris, Éditions Gallimard.

Boyd, Barbara W. 1987. Virtus Effeminata and Sallust's Sempronia. Transactions of the American Philological Association, 117: 183-201.

Butler, Judith. 2007. El Género en Disputa: El feminismo y la subversión de la identidad, Barcelona, Paidós.

Cantarella, Eva. 1996. Pasado Próximo: Mujeres romanas de Tácita a Sulpicia, Instituto de la Mujer de la Universidad de Valencia, Cátedra.

Del Castillo, Álvarez Arcadio. 1976. La Emancipación de la mujer romana en el siglo I d. C., Universidad de Granada.

Despentes, Virginie. 2007. Teoría King Kong, Barcelona, Mesulina.

Dixon, Suzanne. 2004. Exemplary Housewife or Luxurious Slot? En Women's Influence on Classical Civilitation. McHardy, Fiona \& Marshall, Eireann (eds.), 56-74. London \& New York, Routledge.

García González, Alejandro. 2009. En defensa de Celio, Madrid, Cátedra.

Geffcken, Katherine A. 1995. Comedy in the Pro Caelio, Leiden, E. J. Brill.

Harders, Ann-Cathrin. 2005. Zwischen Kooperation und Repräsentation: Bruder- Schwester- Beziehungen in der römischen Republik und mi frühen Prinzipat (2 Jh. v. Chr. - 1 Jh. n. Chr.). Historische Sozialforschung, 30 -3 (113): 61-79.

Hejduk, Julia D. 2008. Clodia. A Sourcebook, University of Oklahoma Press.

Hemelrijk, Emily A. 1999. Matrona Docta. Educated women in the Roman élite from Cornelia to Julia Domna, London \& New York, Routledge.

Joshel, Sandra R. 2002. The Body Female and the Body Politics. En Sexuality and Gender in the Classical World, McClure, K. Laura (ed.), 163-190. Oxford, Blackwell.

López Gregoris Rosario. 1998. Casarse en latín. Determinación de la diátesis léxica matrimonial. Emerita LXVII, pp. 95103.

McCoy, Marsha. 2006. The Politics of Prostitution: Clodia, Cicero, and Social Order in the Late Roman Republic. En Prostitutes \& Courtesans in the Ancient World, Faraone, Christopher A. \& McClure, Laura K. (Eds.), pp. 186- 206. Madison, University of Wisconsin Press.

Moreau, Philippe. 1978. Plutarque, Augustin, Lévi-Strauss: prohibition de l'inceste et mariage préférentiel dans la Rome primitive, Revue belge de Philologie et d'Histoire, 56-1 : 41-54.

Olson, Kelly. 2006. Matrona and Whore: Clothing and Definition in Roman Antiquity. En Prostitutes \& Courtesans in the Ancient World, Faraone, Christopher A. \& McClure, Laura K. (eds.), 186- 206. Madison, University of Wisconsin Press.

Parker, Holt N. 1997. The Teratogenic Grid. En Roman Sexualities, Judith Hallet P. \& Marilyn Skinner B. (eds.), 47-65. Princeton, New Jersey, Princeton University Press.

Pomeroy, Sarah B. 1987. Diosas, Rameras, Esposas y Esclavas, Madrid, Akal.
Prados Torreira, Lourdes. 2001. Una aproximación a los estudios de género a través de la arqueología. En Ideas de Mujer. Facetas de lo femenino en la Antigüedad, López Gregoris, Rosario \& Unceta Gómez, Luis (eds.), 287-315. Alicante, Centro de Estudios sobre la Mujer.

Richlin, Amy. 1993. Feminist Theory and the Classics. New York: Routledge, Thinking Gender series.

Santoro L' Hoir, Francesca. 1992. The Rethoric of Gender Terms, Man, Woman \& The Portrayal of Character in Latin Prose, Leiden, E. J. Brill.

Skinner, Berglund Marilyn. 1983. Clodia Metelli, Transactions of the American Philological Association, 113: 273-287.

Skinner, Berglund Marilyn. 2011. Clodia Metelli: The Tribune's Sister, Oxford University Press.

Veyne, Paul. 2010. Sexo y Poder en Roma. Madrid, Paidós. 